\title{
Socioeconomic condition and dietary habits in relation to oral health in 12-year-old children from Sarajevo, Bosnia-Hercegovina
}

\author{
Zukanović, Amila ${ }^{1}$; Nakaš, Enita ${ }^{2}$; Marković, Nina ${ }^{1}$; Arslanagić, Amra ${ }^{1}$ \\ 1 Department of Preventive and Pediatric Dentistry, School of Dental Medicine, University of Sarajevo \\ 2 Department of Orthodontics, School of Dental Medicine, University of Sarajevo
}

\begin{abstract}
Introduction: Living conditions and socioeconomic status are the significant determinants of oral health. The research goal was to analyze the dietary habits of 12-year-old children in Sarajevo, Bosnia-Hercegovina. Another goal was to investigate the differences in food cariogenicity of children living under different socioeconomic conditions and to determine their relationship with the oral health. Materials and methods: The sample included 109 children, classified in groups of high, average and low socioeconomic status. Based on the survey and examination, data on nutrition and caries experience (DMFT index) were obtained.

Results: There was a difference in dietary habits between children living under different conditions. Children of high socioeconomic status (SES) had a more favorable number of daily meals comparing to children of low socioeconomic status. The average DMFT index, as a measure of caries experience of 12-year-old children amounted 4.8 $( \pm 3.2)$. Children of high socioeconomic status had significantly lower caries experience than those from average and low statuses (high SES DMFT 3,60 $\pm 2,84 \mathrm{SD}$ vs. middle SES

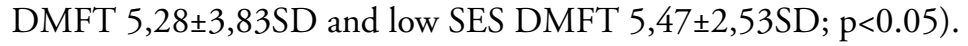

Zukanovic A, Nakas E, Markovic N, Arslanagic A. Socioeconomic condition and dietary habits in relation to oral health in 12-year-old children from Sarajevo, Bosnia-Hercegovina. South Eur J Orthod Dentofac Res. 2018;5(2):5-8.
\end{abstract}

Submitted: July 14, 2018; Revised: September 14, 2018; Published: October 14, 2018

\section{INTRODUCTION}

Nutrition is an important determinant for the risk of caries as proven in the early studies focused on the relationship between caries and dietary habits (frequency of meals and sugar quantity) ${ }^{1}$ but it is not the crucial factor. ${ }^{2,3}$

Correlation between cariogenic meals and caries increase is severely low among examinees with optimal intake of fluoride toothpaste, adequate plaque control and good oral hygiene. ${ }^{4}$ Additionally, Gibson and Williams's research in preschool children indicated that correlation of nutrition (frequency and quantity of cariogenic meals) and caries is present only with children who brush their teeth less than twice a day. ${ }^{5}$

Corresponding Author:

Amila Zukanović

Department of Preventive and Pediatric Dentistry

School of Dental Medicine, University of Sarajevo

Bolnička 4, 71000 Sarajevo, Bosnia and Herzegovina

e-mail:amila.zukanovic@hotmail.com
Use of fluoride toothpaste, good plaque control and developed preventive measures decreases the influence of dietary habits on caries occurrence. An occurrence of caries in some populations is found to be independent of the carbohydrate consumption. ${ }^{6}$ Caries free adolescents in the Netherlands consume large quantities of carbohydrates but also have good oral hygiene and sufficient usage of fluorides. ${ }^{7}$ Same is noted also in other populations (USA, Canada, and England) were examinees have a good level of oral hygiene. ${ }^{8-10}$

Studies performed in developed countries in the past 20 years show weak or no correlation between carbohydrate consumption and caries prevalence. ${ }^{11}$

On the other hand, developing countries or particular groups of persons with high risk for the caries occurrence, show greater dependence between carbohydrate consumption and caries. Researchers showed that although the correlation between dental caries and carbohydrates exists, the correlation degree is different, as well as the significance of nutrition within prevention measures. ${ }^{12-16}$ 
Besides habits related to oral hygiene and fluoride use, the significance of nutrition as one of caries risk factors should be observed regarding general living conditions, economic and cultural status of examinees.

Dental caries is a disease related to social deprivation ${ }^{17-22}$ although the impact of socioeconomic status on oral health differs between countries. Living conditions affect dietary habits, maintenance of oral hygiene, fluoride use, availability of prevention and dental treatment. Socioeconomic factors are important in risk assessment for caries occurrence although they are not directly included in the development of cariogenic lesion on the tooth surface. ${ }^{23}$ Living conditions are considered to be an important caries predictor for children and adults, but according to some researches, the role of socioeconomic status in the caries occurrence is not significant to such an extent. ${ }^{24}$

Research performed in Bosnia and Herzegovina also indicated the existence of a difference in oral health among persons living under different socioeconomic conditions. ${ }^{25-28}$

This research aimed to analyze dietary habits of 12-year-old children in Sarajevo, and to investigate the existence of differences in food cariogenicity of children living under different socioeconomic conditions, and to determine the relationship with the caries experience.

\section{MATERIALS AND METHODS}

Examinees were 12-year-old children from the city of Sarajevo, Bosnia and Herzegovina of different socioeconomic status and living conditions. The total of 109 children, including 49 girls and 60 boys, from three elementary schools, were examined and questioned. Charity private school was selected since all children come from a family with low SES. The second elementary school selected is the private school, where parents must pay monthly scholarship fee for children, which was, according to Institute for statistics of Federation of Bosnia and Herzegovina, higher than the average salary in Federation of Bosnia and Herzegovina (meaning families with high SES). ${ }^{29}$ The third school that was selected is the public elementary school, chosen from the Sarajevo municipality, attended by children that are coming from the families with average SES status. ${ }^{29}$

Since the total amount of the children attending these two private schools was limited (only 35-40 of twelve-year-old pupils in the generation), the total number of children from the public schools was matched to the number of examinees from the private low and private high SES schools. Since there were three classes of 12-years old children in public school, with 30-35 pupils in each class, subjects from the public school were selected randomly.

Even though SES of children was preliminary determined through the attending of each school, socioeconomic status of each child was additionally checked through parent's questionnaire. The questionnaire contained questions about number of family members, family monthly income, and parents' educational level. There was also the question for the parents to classify their families into a group of high/average/low SES. The questionnaire answers were compared with data from a Federal agency for statistics guides and classified in groups of high, middle and low socioeconomic status. No mismatching between answers from the questionnaire and the school attended was found in the groups of high and low SES children. Mismatching between predicted average SES of pupils from the public school and SES determined through parents questionnaire was found and those pupils were excluded $(\mathrm{N}=2)$.

The final sample included 35 children of high socioeconomic status, 36 children of average socioeconomic status while the group of low socioeconomic status included 38 examinees.

All examinees were surveyed through the parent's questionnaire also about the frequency and food cariogenicity. Each answered questionnaire was returned together with signed informed consent by parents.

Examinations were conducted following WHO instructions and criteria for the fieldwork, under the daily light, using the CPI probe and dental mirror. ${ }^{30}$ Dental status was expressed through the DMFT index as a measure of caries experience.

The following methods of statistical analysis were used in the processing of research results: percentages, arithmetic mean, standard deviation, Student $t$ test, $\chi 2$ test and Spearman correlation. SPSS 15.0 (SPSS, Inc, Chicago, Il) statistical program was used for data processing.

\section{RESULTS}

Table 1. Number of daily meals of children with different socioeconomic status

\begin{tabular}{ccccccccc}
\hline \multirow{2}{*}{$\begin{array}{c}\text { Number of } \\
\text { daily meals }\end{array}$} & \multicolumn{2}{c}{ High SES } & \multicolumn{2}{c}{ Low SES } & \multicolumn{2}{c}{ Average SES } & \multicolumn{2}{c}{ Total } \\
\cline { 2 - 9 } & $\mathbf{n}$ & $\%$ & $\mathbf{n}$ & $\%$ & $\mathbf{n}$ & $\%$ & $\mathbf{n}$ & $\%$ \\
\hline $\mathbf{3 - 4}$ meals & 3 & 8.6 & 1 & 2.6 & - & - & 4 & 3.7 \\
\hline $\mathbf{4 - 5}$ meals & 21 & 60.0 & 15 & 39.5 & 12 & 33.3 & 48 & 44.0 \\
\hline $\mathbf{6 - 7}$ meals & 8 & 22.9 & 11 & 28.9 & 17 & 47.2 & 36 & 33.0 \\
\hline$>$ 7 meals & 3 & 8.5 & 11 & 28.9 & 7 & 19.5 & 21 & 19.3 \\
\hline Total & 35 & 100 & 38 & 100 & 36 & 100 & 109 & 100 \\
\hline
\end{tabular}

Table 1 indicates a number of daily meals of children of different socioeconomic status. Children of low socioeconomic status have the highest number of meals per day (almost 29\% of children take more than seven meals a day), in comparison to children of high socioeconomic status where only $8.5 \%$ examinees take more than seven meals a day. Children of high socioeconomic status have a more favorable number of daily meals, in comparison to children of low socioeconomic status. Responses to the question concerning the number of daily meals of children with high socioeconomic status significantly differ from responses of children with average socioeconomic status $(\chi 2=4.619, \mathrm{p}<0.01)$, as well as responses of children with high socioeconomic status in relation to children of low socioeconomic status $(\chi 2=7.197, \mathrm{p}<0.05)$. The difference in the responses of children with low socioeconomic status and children of average socioeconomic status is not statistically significant $(\chi 2=$ 2.323, $\mathrm{p}>0.05)$. 
Table 2. Frequency of taking candies of children with different socioeconomic status

\begin{tabular}{ccccccccc}
\hline & \multicolumn{2}{c}{ High SES } & \multicolumn{2}{c}{ Low SES } & \multicolumn{2}{c}{ Average SES } & \multicolumn{2}{c}{ Total } \\
\cline { 2 - 9 } & $\mathbf{n}$ & $\%$ & $\mathbf{n}$ & $\%$ & $\mathbf{n}$ & $\%$ & $\mathbf{n}$ & $\%$ \\
\hline Never & - & - & - & - & - & - & - & - \\
\hline Once a week & 3 & 8.6 & 1 & 2.6 & - & - & 4 & 3.7 \\
\hline $\begin{array}{c}\mathbf{2} \text { - 3 times a } \\
\text { week }\end{array}$ & 12 & $34 . .3$ & 7 & 18.4 & 8 & $22 . .2$ & 27 & 24.8 \\
\hline $\begin{array}{c}\mathbf{4}-\mathbf{5} \text { times a } \\
\text { week }\end{array}$ & 2 & 5.7 & 7 & 18.4 & 11 & 30.6 & 20 & 18.3 \\
\hline $\begin{array}{c}\text { Every day } \\
\text { Several times } \\
\text { a day }\end{array}$ & 16 & 45.7 & 19 & 50.0 & 7 & 19.4 & 42 & 38.5 \\
\hline Total & 35 & 100 & 38 & 100 & 36 & 100 & 109 & 100 \\
\hline
\end{tabular}

Table 2 presents responses to the question of frequency of candy consumption, that is, food cariogenicity.

The difference in responses of children of high socioeconomic status and children of low socioeconomic status is not statistically significant $(\chi 2=3,798, p>0.05)$, or between children of low socioeconomic status and children of average socioeconomic status $(\chi 2=1.606, p>0.05)$. Responses to the question of frequency of candy consumption of children of high socioeconomic status significantly differ from responses of children with average socioeconomic status $(\chi 2=7.231$, $\mathrm{p}<0.05)$. A large number of children of middle socioeconomic status take candies several times a day $(28 \%)$, in comparison to children of high socioeconomic status, where only $5 \%$ of children take candies several times a day.

Table 3. Values of DMF index of children with different socioeconomic status

\begin{tabular}{ccccc}
\hline \multicolumn{5}{c}{ Average DMF values } \\
\hline & High SES & Low SES & Average SES & Total \\
\hline Mean (SD) & $3.60(2.84)$ & $5.47(2.53)$ & $5.28(3.83)$ & $4.81(3.22)$ \\
\hline
\end{tabular}

Table 3 presents average DMFT values of children of different socioeconomic status.

Caries experience of 12-year-old children in Sarajevo is 4.8( \pm 3.2$)$. Children of high socioeconomic status have the lowest DMFT index values in comparison to children of the remaining two groups. The difference in the DMFT index of children of high socioeconomic status and children of low socioeconomic status is statistically significant $(\mathrm{t}=2.968, \mathrm{p}<0.01)$, as well as among children of high and children of average socioeconomic status $(t=2.099, \mathrm{p}<0.05)$. There is no significant difference in the value of the DMFT index between children of low and average socioeconomic status $(t=2.099, \mathrm{p}>0.05)$.

Correlation between the socioeconomic statuses of examinees, DMFT index, and dietary habits was tested. Correlation between the socioeconomic status and oral health was noted - children of low socioeconomic status have significantly higher DMFT index values (Spearman rho $=-0.270, \mathrm{p}<0.01$ ).

Correlation between the socioeconomic status and nutrition was also noted, children of low socioeconomic status also have a higher number of daily meals (Spearman rho $=-0.251, \mathrm{p}<0.05$ ).

\section{DISCUSSION}

Available data for our population indicates that Bosnia and Herzegovina is a country of risk regarding to caries prevalence. ${ }^{27-28}$ Primary reasons for this include lack of long-term prevention programs, poorly organized dental services, low socioeconomic status of the population and changed living conditions during the war. Caries experience (DMFT) of children aged 12-15 years from Sarajevo was 6.5 in $1990^{31}$, and for children of the same age in 1999, DMFT was 7.2. ${ }^{32}$ According to an examination conducted on the part of the territory of B-H in 1997, caries experience of 12-yearold children was 6.2. ${ }^{33}$ The caries experience of 12 -year-olds in B-H in 2004 was 4.16 which is the closest value to one registered in our research. ${ }^{33}$ It seems that oral health significantly improved over the last 15 years but is difficult to explain the reasons behind. On a state level, there were no oral disease prevention programs or oral health promotion programs implemented. A possible explanation could be that WHO methodology was followed in our study as well as in the one conducted in 2004. Usage of CPI probe for caries detection that lowers the number of diagnosed caries lesions could be a possible explanation for lower values of average DMFT.

The significance of nutrition as an etiological factor for caries has been rediscussed in the past twenty years. Children of developed countries have far fewer carries, regardless of the higher carbohydrate consumption. This fact is linked to improvement of habits regarding oral hygiene, as well as the widespread use of fluoride in those countries. ${ }^{34}$ In populations in which plaque control is insufficient and there is a lack of regular and proper use of fluoride and good oral hygiene habits, the correlation between caries and diet can be identified. In such populations values of DMFT increase with increased sugar consumption ${ }^{34}$, which is in accordance with our findings.

According to our results, most children, over $50 \%$, take candies once or several times a day. Dietary habits among children of different socioeconomic status significantly differ. Children with low socioeconomic status are far ahead regarding taking candies every day or several times a day (60.5\%), although the corresponding percentage of examinees is in the category of average (47.2\%) and high socioeconomic status $(51.4 \%)$ cannot be considered as acceptable. Bad nutrition habits, especially concerning candy intake, is less present within children of higher socioeconomic status ${ }^{35}$ as it was also the case among our examinees in high SES group.

Regarding the number of meals taken during the day it is recommended not to exceed the amount of 4-5 food intakes daily. The higher intake indicates a higher number of acid attacks on teeth, which might cause the initial tooth demineralization. Results of this research indicated that less than half of our children (44\%) have 4-5 meals a day compared to more than half of Swedish children according to Peterson study. ${ }^{36}$ Around $33 \%$ of our examinees have 6-7 meals a day. 
Differences between frequencies of meals taken during the day were noted in regards to SES of our examinees. In the group of children with high socioeconomic status most children, around $60 \%$, have 4 to 5 meals a day and around $30 \%$ of children have six meals and more.

Children of low socioeconomic status have somewhat worse dietary habits. The highest number (58\%) of children has 6 and more meals a day, whereas $40 \%$ have $4-5$ meals a day.

Children from the group of average socioeconomic status have the least favorable eating habits, $67 \%$ of children have 6 and more meals a day.

According to Cury et al., dental plaque created in case of exposure to food enriched with carbohydrates eight times a day have higher cariogenicity. Additionally, in such cases the cariostatic effect of fluoridated drinking water is missing. The loss of enamel minerals is significantly larger than in the case when the number of daily meals with carbohydrates is from 2-4. ${ }^{35}$

Fluoride programs are insufficient in our country, drinking water is not fluoridated and habits of our population regarding oral hygiene are far from the ideal. Poor dietary habits are a significant caries risk factor for our children as opposed to children living in developed countries where the impact of diet on caries occurrence is reduced to a minimum.
According to the results of this research particular attention should be paid to the education of our children on proper oral hygiene and proper nutrition within prevention programs, and especially with children of low SES.

\section{CONCLUSION}

Oral health of B-H children is improved in the last 15 years according to epidemiological data available. This must be interpreted with caution since there are no objective reasons for the improvement. One must consider that different methodology of collecting data (usage of CPI probe in accordance with WHO methodology) could be the reason behind. However, even the latest registered values of DMFT are placing B-H in medium caries risk country.

Socioeconomic status is a significant oral health determinant in our country. There are differences in the dietary habits of children living in different living conditions. Children of low socioeconomic status have significantly worse oral health in comparison to children of high socioeconomic status, whereby bad dietary habits (increased number of meals per day and more frequent candy consumption) present a significant risk factor for oral caries.

Conflict of interest: none declared

\section{LITERATURE}

1. Gustafson B, Quensel C, Lanke L. The Vipeholm dental caries study: the effects of different carbohydrate intake of caries activity in 436 individuals observed for five years. Acta Odontol Scand. 1954;11:232-64.

2. Walker ARP, Cleaton - Jones PE. Sugar intake and dental caries: where do we stand? J Dent Child. 1989;56:30-5.

3. König KG. Diet and oral health. Int Dent J. 2000;50:162-74.

4. Van Loveren C, Duggal MS. Dental considerations for dietary counseling. Int Dent J. 2001;51(6):408-412.

5. Gibson S, Williams S. Dental caries in pre - school children: associations with social class, toothbrushing habit and consumption of sugars and sugar - containing foods. Further analysis of data from the national diet and nutrition survey of children aged $1.5-4.5$ years. Caries Res. 1999;33:93-170.

6. Morikava FS, Fraiz FC, Gil GS, de Abreu MHNG, Ferreira FM. Healthy and cariogenic foods consumption and dental caries: A preschool-based cross-sectional study. Oral Dis. 2018;24(7):1310-1317

7. Truin GJ, König KG, Bronkhorst EM, Frankenmolen F, Mulder J, Van't Hof MA. Time trends in caries experience of 6- and 12-year-old children of different socioeconomic status in The Hague. Caries Res. 1998;32(1):1-4.

8. Rugg-Gunn AJ, Hackett AF, Appleton DR, Jenkins GN, Eastoe JE. Relationship between dietary habits and caries increments assessed over two years in 405 English adolescent school children. Arch Oral Biol. 1984;2:983-992.

9. Burt BA, Eklund SA, Morgan KJ, Larkin FE, Guire KE, Brown JLO, Weintraub JA. The effects of sugars intake and frequency of ingestion of dental caries increment in a threeyear longitudinal study. J Dent Res. 1988;6:1422-1429.

10. Lachapelle D, Couture C, Brodeur JM, Servingy J. The effects of nutritional quality and frequency of consumption of sugary foods on dental caries increment. Can J Pub Health. 1990;81:370-375.

11. Duggal MS, van Loveren C. Dental considerations for dietary counseling. Int Dent J. 2001;51(6 Suppl 1):408-12.

12. van Loveren C, Duggal MS. The role of diet in caries prevention. Int Dent J. 2001;51(6 Suppl 1):399-406.

13. Zero D, Fontana M, Lennon A. Clinical applications and outcomes of using indicators of risk in caries management. J Dent Educ. 2001; 65(10):1126-32.

14. Montero J, Costa J, Bica I, Barrios R. Caries and quality of life in Portuguese adolescents: Impact of diet and behavioral risk factors. J Clin Exp Dent. 2018;10(3):218-223.

15. Aldwell K, Caillaud C, Galy O, Frayon S, Allman-Farinelli M. Tackling the Consumption of High Sugar Products among Children and Adolescents in the Pacific Islands: Implications for Future Research. Healthcare (Basel). 2018;6(3). pii: E81.

16. Paglia L. WHO: healthy diet to prevent chronic diseases and caries. Eur J Paediatr Dent. 2018;19(1):5.

17. Watson MR, Horowitz AM, Garcia I, Canto MT. Caries conditions among 2-5 years old immigrant Latino children related to parent's oral health knowledge, opinions, and

practices. Community dent oral epidemiol. 1999;27(1):8-15.

18. Evans RW, Lo EO, Darvell DW. Determinants of variation in dental caries experience in primary teeth of Hong Kong children aged 6-8 years. Community dent oral epidemiol. 1993; 21(1):1-3

19. Milen A. Role of social class in caries occurence in primary teeth. Int J Epidemiol. 1987; $16(2): 252-6$.

20. Jones CM, Woods K, Taylor GO. Social deprivation and tooth decay in Scotish schoolchildren. Health Bull. (Edinb) 1997;55(1):11-5.

21. The effectiveness of water Fluoridation.Canbera: Australian Government Printing Office. NHMRC (National Health and Medical Research Council) 1991.

22. Treasure ET. Dever J. The prevalence of caries in 5 year old children living in fluoridated and non-fluoridated communities in New Zealand. N Z Dent J. 1992 Jan;88(391):9-13.

23. Beck JD. Risk revisited. Community Dent Oral Epidem 1998;26:220-5.

24. Curtis AM, Cavanaugh JE, Levy SM, VanBuren J, Marshall TA, Warren JJ. Examining caries aetiology in adolescence with structural equation modelling. Community Dent Oral Epidemiol. 2018;46(3):258-264.

25. Zukanovic A, Habibovic J, Habibovic E, Ajanovic M, Bajric E. Evaluation of Dental Fear and Anxiety in Displaced Persons in Bosnia and Herzegovina. Acta Stomatol Croat. 2018;52(2):140-147.

26. Zukanovic A, Habibovic J, Habibovic E, Ajanovic M. Oral health status among displaced and domicile persons in Bosnia and Herzegovina. Dental Gazette 2017;6(1-2):9-16.

27. Huseinbegović A. Social-medical aspect of deciduous teeth caries in urban conditons[Master Thesis]. Sarajevo: University in Sarajevo; 2001.

28. Selimović - Dragaš M. The impact of environment to oral health condition of displaced children[Master Thesis]. Sarajevo: University in Sarajevo; 2002.

29. Institute for statistics of Federation of Bosnia and Herzegovina. Federation of Bosnia and Herzegovina in figures. Sarajevo. 2015.

30. Oral Health Surveys:Basic methods. 4th ed. Geneva:WHO;1997.

31. Maglajlić N, Hatibović Š, Gojković R. Program of Preventive Dentistry in the SR BiH. In: Rajić Z, Editor. Preventive Dentistry Programs. Zagreb: JUMENA;1990.

32. Kobašlija $S$, Maglajlić N, Huseinbegović A, Tahmiščija H. Caries prevalence of children in Sarajevo. Acta Stomatol Croat. 2000;34(1):83-85.

33. Muratbegović A, Marković N, Kobašlija S, Zukanović A. Oral Health Indices and Molar Incisor Hypomineralization in 12 Year Old Bosnians. Acta Stomatol Croat. 2008;42(2):155-163.

34. Woodward M, Walker ARP. Sugar consumption and dental caries: evidence from 90 countries. Br Dent J. 1994;176:297-30.

35. Cury A, Francisco B, Del Bel Cury A, Tabchoury PM. In situ study of sucrose exposure, mutans streptococci in dental plaque and dental caries. Braz Dent J. 2001;12(2):101-104.

36. Petersson GH, Fure $S$, Twetman D, Bratthall D. Comparing caries risk factors and caries risk profiles in children and elderly. Assessing Caries risk. Swed Dent J. 2004;28(3):119-28. 